\title{
Five Years Trend of Helicobacter Pylori Infection Among Dyspeptic Patients in Asella Teaching and Referral Hospital, Arsi University, Ethiopia
}

\author{
Million Getachew Mesfun ${ }^{1, ~}$, Shimels Teshome ${ }^{2}$, Desalegn Alemu ${ }^{2}$ \\ ${ }^{1}$ Department of Medical Laboratory Science, college of Health Sciences, Arsi University, Asella, Ethiopia \\ ${ }^{2}$ Asella Teaching and Referral Hospital, Arsi University, Asella, Ethiopia \\ Email address: \\ milliongetachew23@gmail.com (M. G. Mesfun) \\ ${ }^{*}$ Corresponding author
}

To cite this article:

Million Getachew Mesfun, Shimels Teshome, Desalegn Alemu. Five Years Trend of Helicobacter Pylori Infection Among Dyspeptic Patients in Asella Teaching and Referral Hospital, Arsi University, Ethiopia. Science Journal of Clinical Medicine. Vol. 7, No. 5, 2018, pp. 37-40. doi: $10.11648 /$ j.sjcm.20180705.11

Received: October 9, 2018; Accepted: November 29, 2018; Published: December 18, 2018

\begin{abstract}
Infectious diseases such as $H$. pylori infection are major public health problems in Ethiopia. Even though there are a considerably large number of dyspeptic patients in Asella teaching and referral hospital, there is no study done to assess the trend of $H$. pylori infection among dyspeptic patients. The objective of this study was to assess a five years trend of $H$. pylori infection among dyspeptic patients in Asella teaching and referral hospital. A retrospective cross-sectional study design was used to assess the trend of $H$. pylori infection from January 1, 2013 until October 30, 2017 among dyspeptic patients by counting stool antigen test results from the laboratory log book. It was found that a total of 9,493 dyspeptic patients with the mean age of 33.9 ( $\mathrm{SD}+15.1)$ years were test for H. pylori infection in the last five years in Asella teaching and referral hospital. The total prevalence of $H$. pylori was 1,444 (15.2\%) in which $863(59.8 \%)$ of them were females and $581(40.2 \%)$ were males. There was a fluctuating trend of $\mathrm{H}$. pylori with annual total cases of $H$. pylori ranged from $19.3 \%$ in 2017 to $6.1 \%$ in 2015 . The study showed that there was low prevalence of $H$. pylori infection among dyspeptic patients in Asella teaching and referral hospital, Ethiopia. The low prevalence reported from this study could be also due to the quality of the test kits, therefore, there is a need to validate the test kits used by the hospital laboratory.
\end{abstract}

Keywords: H. pylori, Trend, Dyspeptic Patients, Asella, Ethiopia

\section{Background}

Helicobacter pylori (H. pylori) is a spiral shaped gram negative bacillus. The ecological niche of $H$. pylori is the stomach where the organism establishes long term colonization of the gastric mucosa [1]. Chronic H. pylori infection is associated with chronic gastritis, peptic ulcer disease, Mucosal Associated Lymphoid Tissue (MALT) lymphoma and gastric adenocarcinoma. H. pylori is also classified as a class 1 carcinogen because of its causal relationship to gastric adenocarcinoma, one of the world's deadliest cancers [2].

More than half of world's population is chronically infected with $H$. pylori, with the highest prevalence in developing countries, reaching up to $90 \%$ in some populations. H. pylori infection is strongly associated with poor socioeconomic standard and is considered as povertyrelated disease. The acquisition of $H$. pylori infection occurs mainly in childhood and persists lifelong in the absence of effective eradication treatment [3]. In Gambia, $84 \%$ of children were colonized by 30 months of age [4]. The exact route of transmission is not clear, but person-to-person transmission is likely to be a combination of fecal-oral and oral-oral routes. H. pylori strains are usually isolated from gastric biopsy tissue, but it is also possible for the bacterium to be isolated from saliva, gastric reflux fluid, and vomits [5].

Infectious diseases such as $H$. pylori infection are major public health problems in Ethiopia and dyspepsia is one of the commonest complaints in any Ethiopian hospital outpatient department. The overall sero-prevalence of $H$. 
pylori infection in adult dyspeptic patients in Ethiopia ranges from $52.4 \%$ [6] to $83.3 \%$ [7]. As the number of gastrointestinal complaints is increasing there is a need to systematically assess the trend of the disease and plan better strategies to at least minimize the incidence rate of the disease among the community.

There was no data about the prevalence and trend of $H$. pylori infection in the study area. Therefore, the aim of this study was to assess the trend of $H$. pylori infection in the last five years among dyspeptic patients in Asella teaching and referral hospital.

\section{Methods}

\subsection{Study Design and Area}

This study was conducted in Asella teaching and referral hospital which is located at $175 \mathrm{~km}$ to the south east of the capital city, Addis Ababa. The hospital provides different inpatient and outpatient services to more than 3 million people in the region. A retrospective cross-sectional study design was used to assess the trend of $H$. pylori infection among dyspeptic patients in the hospital.

\subsection{Study Population and Sample Size}

Data of all dyspeptic patients who were tested for $H$. pylori stool antigen test from January 1, 2013 until October 30, 2017 were collected. Laboratory data which were not fully documented were excluded.

\subsection{Laboratory Test}

H. pylori test was done in Asella teaching and referral hospital laboratory based on the detection of $H$. pylori derived antigens from stool sample using different rapid tests. Wondfo one step H.pylori feces Test (Guangzhou Wondfo Biotech Co., Ltd. China) was commonly used in the hospital laboratory in the last five years.

\subsection{Data Collection and Statistical Analysis}

Data including $H$. pylori test result, age, sex and the department which orders the $H$. pylori test were collected from the log book of the parasitology laboratory. Collected data was entered in SPSS version 20 for analysis. Prevalence of $H$. pylori infection among different age groups and sex was analyzed by simple frequency distribution. Chi-square analysis was used to identify significant predictors. A $P$-value of $<0.05$ was considered as statistically significant.

\subsection{Ethical Consideration}

Ethical clearance was obtained from Arsi University, college of health science ethical review committee and data was used only for this study purpose.

\section{Results}

\subsection{Demographic Characteristics and Prevalence of $\boldsymbol{H}$. Pylori Among the Study Participants}

A total of 9,493 dyspeptic patients were test for $H$. pylori infection in the last five years in Asella teaching and referral hospital. Among them, 5,956 (62.7\%) were females and $3,537(37.3 \%)$ were males. The mean age of the study subjects was $33.9(\mathrm{SD} \pm 15.1)$ years with age ranging from 1 to 96 years. More than half of those dyspeptic patients 5,151 $(54.3 \%)$ were young adults under 30 years (Table 1$)$.

\subsection{Prevalence of H. Pylori Infection Among Dyspeptic Patients}

The total prevalence of $H$. pylori was $15.2 \%(n=1,444)$ in which $59.8 \%(n=863)$ of them were females and $40.2 \%$ $(\mathrm{n}=581)$ were males. There was higher $H$. pylori prevalence among male patients $(16.4 \%)$ than female patients $(14.5 \%)$ and this difference in $H$. pylori prevalence between male and female patients were statistically significant $(p=0.012)$. Highest prevalence of $H$. pylori was recorded among dyspeptic patients with age less than or equal to 20 years $(18.0 \%)$ and lowest prevalence of $H$. pylori infection was recorded among patients older than 60 years (10.9\%) (Table $1)$.

Table 1. Prevalence of H. pylori infection among dyspeptic patients in Asella teaching and referral Hospital, Ethiopia, 2017.

\begin{tabular}{|c|c|c|c|}
\hline \multirow[t]{2}{*}{ Variable } & \multicolumn{2}{|l|}{ H. pylori } & \multirow[t]{2}{*}{ P-Value } \\
\hline & Positive N (\%) & Negative N (\%) & \\
\hline \multicolumn{4}{|l|}{ Sex } \\
\hline Female & $863(14.5)$ & $5093(85.5)$ & \multirow[t]{2}{*}{0.012} \\
\hline Male & $581(16.4)$ & $2956(83.6)$ & \\
\hline \multicolumn{4}{|l|}{ Age group } \\
\hline$<=20$ & $338(18.0)$ & $1540(82.0)$ & \multirow{6}{*}{$<0.001$} \\
\hline $21-30$ & $482(14.7)$ & $2791(85.3)$ & \\
\hline $31-40$ & $270(14.9)$ & $1546(85.1)$ & \\
\hline $41-50$ & $193(16.2)$ & $1002(83.8)$ & \\
\hline $51-60$ & $99(13.0)$ & $661(87.0)$ & \\
\hline$>60$ & $62(10.9)$ & $509(89.1)$ & \\
\hline \multicolumn{4}{|l|}{ Year } \\
\hline 2013 & $133(10.6)$ & $1121(89.4)$ & \multirow{5}{*}{$<0.001$} \\
\hline 2014 & $128(11.1)$ & 1023(88.9) & \\
\hline 2015 & $37(6.1)$ & $574(93.9)$ & \\
\hline 2016 & $634(16.6)$ & $3184(83.4)$ & \\
\hline 2017 & $512(19.3)$ & $2147(80.7)$ & \\
\hline \multicolumn{4}{|l|}{$\begin{array}{l}\text { Department of } \\
\text { examination }\end{array}$} \\
\hline Emergency OPD & $332(18.9)$ & $1426(81.1)$ & \multirow{8}{*}{$<0.001$} \\
\hline Gyn OPD & $10(27.0)$ & $27(73.0)$ & \\
\hline Medical OPD & $986(13.6)$ & $6258(86.4)$ & \\
\hline ART clinic & $57(30.8)$ & $128(69.2)$ & \\
\hline $\mathrm{MCH}$ & $3(75.0)$ & $1(25.0)$ & \\
\hline Pedatric ward & $7(26.9)$ & $19(73.1)$ & \\
\hline Medical ward & $38(20.7)$ & $146(79.3)$ & \\
\hline Gyn ward & $11(20.0)$ & $44(80.0)$ & \\
\hline
\end{tabular}




\subsection{Five Years Trend of Helicobacter Pylori Infection Among Dyspeptic Patients}

There was a fluctuating trend of $H$. pylori infection in the last five years, with annual total cases of $H$. pylori ranged from $6.1 \%$ in 2015 to $19.3 \%$ in 2017 . There was statistically significant inter-annual variation of $H$. pylori occurrence in the study area $(p<0.001)$. There was a significant incline in the prevalence of $H$. pylori in 2017 compared to 2013 ( $p<$ 0.012 ). There was successive increase in prevalence from 2013 onwards with an exceptional decline in 2015 (Figure 1).

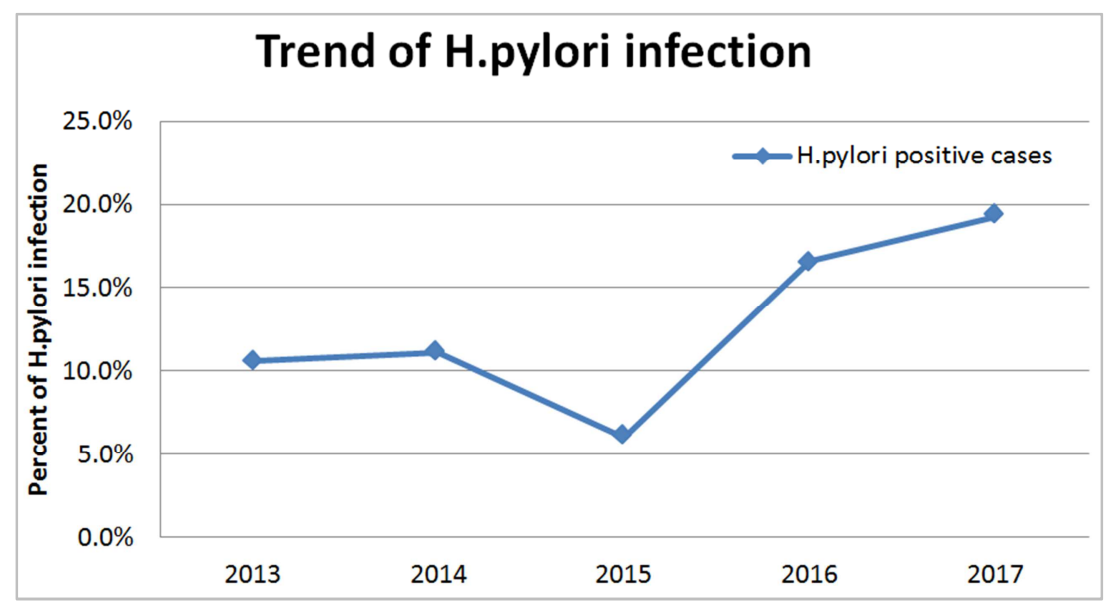

Figure 1. Trend of H. pylori from 2013 to 2017 among dyspeptic patients in Asella teaching and referral hospital , Arsi University, Ethiopia.

In each year the prevalence of $H$. pylori was higher among male than female patients (Figure 2)

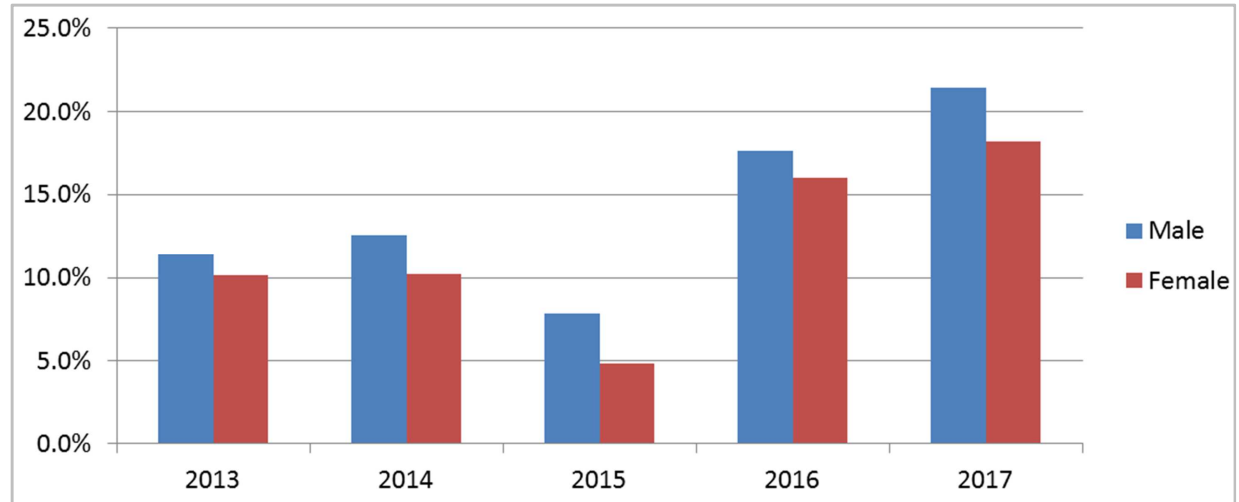

Figure 2. Distribution of H. pylori infection among male and female dyspeptic patients from 2013 to 2017 in Asella teaching and referral hospital , Arsi University, Ethiopia.

\section{Discussion}

From 2013 - 2017, a total of 9,493 dyspeptic patients were tested for $H$. pylori infection in Asella teaching and referral hospital using stool antigen test. This retrospective data showed that only $15.2 \%$ of the dyspeptic patients were positive for $H$. pylori infection. This prevalence was very low in contrast to previous sero-prevalence reports from various hospitals [8-12]. It was also lower than the report from Tikur Anbassa University Hospital, where the prevalence of $H$.pylori among adult patients with dyspepsia using stoolantigen tests was $81 \%$ [13]. This difference could be due to a lack of sensitivity in the test kit used by our hospital laboratory.

Many studies showed that the prevalence of $H$. pylori was higher among older age groups [8, 14, 15] and this was different to the current study result in which prevalence of $H$. pylori infection was higher among young age participants $(p<0.001)$. H. pylori infection was more frequent among male participants and this finding was similar to the finding from Korea [14], Gondar, Ethiopia [8], and Bahr Dar, Ethiopia [10].

The majority of the $H$. pylori positive patients 1,388 $(96.1 \%)$ were from the outpatient department and only 56 (3.9\%) were admitted patients. It has been reported that the prevalence of $H$. pylori related complications are lower in developing countries than developed countries. Huge number of patients carries the bacteria but don't experience its consequences in developing countries [16].

There was an annual fluctuation of $H$. pylori prevalence with minimum $(6.1 \%)$ and maximum $(19.3 \%)$ prevalence in 2015 and 2017, respectively. There was statistically significant incline in the prevalence of $H$. pylori from 2015 to $2017(\mathrm{p}=0.011)$. This was a different finding compared to other similar studies done in Ethiopia [10, 13]. 


\section{Conclusion}

Compared to the national report, there was very low prevalence of $H$. pylori infection among dyspeptic patients in Asella teaching and referral hospital, Ethiopia. The low prevalence reported from this study could be due to the technical errors or low quality of the test kits; therefore, there is a need to validate the test kits used by the hospital laboratory.

\section{Acknowledgements}

The authors would like to thank all the laboratory staff at the Asella teaching and referral Hospital for their invaluable support during data collection.

\section{Author Contributions}

All authors listed, have made substantial, direct and intellectual contribution to the work, and approved it for publication.

\section{Conflict of Interest}

The authors declare that they have no competing interests.

\section{References}

[1] Celli JP, Turner BS, Afdhal NH, et al. Helicobacter pylori moves through mucus by reducing mucin viscoelasticity. Proceedings of the National Academy of Sciences. 2009; 106(34): 14321-14326. doi: http:// dx.doi.org/10.1073/pnas.0903438106.

[2] Kusters JG, van Vliet AHM, Kuipers EJ. Pathogenesis of Helicobacter pylori Infection. Clinical Microbiology Reviews. 2006; 19(3): 449-490. doi: http://dx.doi. org/10.1128/CMR.00054-05.

[3] Percival SL. The Significance of Helicobacter Pylori Acquisition and the Hygiene Hypothesis. In: Microbiology and Aging: Clinical Manifestations. Totowa, NJ: Humana Press. New York: Springer; 2009; 263-274.

[4] Thomas JE, Dale A, Harding M, Coward WA, Cole TJ, Weaver LT. Helicobacter pylori Colonization in Early Life. Pediatric Research. 1999; 45(2): 218-223. doi: http://dx.doi.org/10.1203/00006450-199902000-00010.

[5] Kusters, J. G., A. H. M. van Vliet, and E. J. Kuipers, Pathogenesis of Helicobacter pylori Infection. Clinical Microbiology Reviews, 2006; 19(3): 449-490. doi: http:// dx.doi.org/10.1128/cmr.00054-05.

[6] Kibru D, Gelaw B, Alemu A, Addis Z. Helicobacter pylori infection and its association with anemia among adult dyspeptic patients attending Butajira Hospital, Ethiopia. BMC Infectious Diseases. 2014; 14(1). doi: http://dx.doi.org/10.1186/s12879-014-0656-3.

[7] Tadesse E, Daka D, Yemane D, Shimelis T. Seroprevalence of Helicobacter pylori infection and its related risk factors in symptomatic patients in southern Ethiopia. BMC Research Notes. 2014; 7(1): 834. doi: http://dx.doi.org/10.1186/17560500-7-834.

[8] Mathewos B, Moges B, Dagnew M. Seroprevalence and trend of Helicobacter pylori infection in Gondar University Hospital among dyspeptic patients, Gondar, North West Ethiopia. BMC Research Notes. 2013; 6(1): 346. doi: http://dx.doi.org/10.1186/1756-0500-6-346.

[9] Watanabe $\mathrm{M}$, Ito $\mathrm{H}$, Hosono $\mathrm{S}$, et al. Declining trends in prevalence of Helicobacter pylori infection by birth year in a Japanese population. Cancer Sci. 2015; 106(12): 1738-1743. doi: http://dx.doi. org/10.1111/cas.12821

[10] Workineh M, Andargie D. A 5-year trend of Helicobacter pylori seroprevalence among dyspeptic patients at Bahir Dar Felege Hiwot Referral Hospital, Northwest Ethiopia. Research and Reports in Tropical Medicine. 2016; Volume 7: 17-22. doi: http://dx.doi. org/10.2147/RRTM.S105361.

[11] Abebaw W, Kibret M, Abera B. Prevalence and Risk Factors of H. pylori from Dyspeptic Patients in Northwest Ethiopia: A Hospital Based Cross-sectional Study. Asian Pacific Journal of Cancer Prevention. 2014; 15(11): 4459-4463. doi: http://dx.doi. org/10.7314/APJCP.2014.15.11.4459.

[12] Negash, M., H. Wondifraw Baynes, and D. Geremew, Helicobacter pylori Infection and Its Risk Factors: A Prospective Cross-Sectional Study in Resource-Limited Settings of Northwest Ethiopia. The Canadian journal of infectious diseases \& medical microbiology = Journal canadien des maladies infectieuses et de la microbiologie medicale, 2018. 2018: p. 9463710-9463710.

[13] Asrat D, Nilsson I, Mengistu Y, et al. Prevalence of Helicobacter pylori infection among adult dyspeptic patients in Ethiopia. Ann Trop Med Parasitol. 2004; 98(2): 181-189. doi: http://dx.doi. org/10.1179/000349804225003190.

[14] Lim SH, Kwon J-W, Kim N, et al. Prevalence and risk factors of Helicobacter pylori infection in Korea: Nationwide multicenter study over 13 years. BMC Gastroenterology. 2013; 13(1). doi: http://dx.doi. org/10.1186/1471-230X-13104.

[15] Moges F. Seroprevalence of Helicobacter pylori in dyspeptic patients and its relationship with HIV infection, ABO blood groups and life style in a university hospital, Northwest Ethiopia. World Journal of Gastroenterology. 2006; 12(12): 1957. doi: http:// dx.doi.org/10.3748/wjg.v12.i12.1957.

[16] Segal I. Persistent low prevalence of Western digestive diseases in Africa: confounding aetiological factors. Gut. 2001; 48(5): 730-732. doi: http://dx.doi. org/10.1136/gut.48.5.730. 